\title{
Smoke-free homes: The final frontier
}

\author{
Rumana Huque ${ }^{1,2}$, Kamran Siddiqi ${ }^{3}$
}

Over 1.2 billion tobacco users worldwide and almost 8 million tobacco-related deaths make tobacco control a public health high priority ${ }^{1}$. While the number of smokers has fallen in high-income countries (HICs) in recent years, the number of tobacco users in many low- and middle-income countries (LMICs) has steadily increased $^{2}$. In addition to active smoking, inhalation of secondhand smoke (SHS) is a major cause of premature death and disease, especially among women and children $^{3,4}$. More than one-third of women ${ }^{5}$ and half of the children ${ }^{6}$ are exposed to SHS worldwide. The exposure to SHS during pregnancy is also high in many countries; the prevalence ranging from $6 \%$ in Nigeria to $73 \%$ in Armenia ${ }^{7}$.

The adverse health consequences of SHS exposure are well documented ${ }^{4,8-10}$. Exposure to SHS increases the risk of acquiring lower respiratory tract and middle-ear infections, invasive meningococcal disease, TB and incident cases, and recurrent episodes and increased severity of asthma among children ${ }^{10}$. Children living in smoking households are at risk of lower academic performance and a high rate of smoking uptake in later life ${ }^{11}$. SHS exposure during pregnancy can cause pregnancy complications, a modest reduction in birth weight, preterm delivery, stillbirths, and infant deaths ${ }^{10}$.

\section{Level of SHS exposure at home}

Private homes remain a major source of SHS exposure particularly for women and children. According to Global Adult Tobacco Surveys in Bangladesh, China, India and Indonesia, $36.5 \%{ }^{11}, 38 \%^{12}, 39.3 \%^{13}$ and $75.4 \%^{14}$ of adult women are exposed to SHS at home, respectively. Globally, about $40 \%$ of children aged less than 14 years are also exposed to SHS within their homes ${ }^{15}$ and these estimates are much higher for LMICs in the South-East Asia, Western Pacific and Eastern Mediterranean regions. Studies that validated SHS exposure level using biomarkers have found even higher levels of SHS exposure among women and children ${ }^{3,16-18}$. In Bangladesh, 95\% of school children in urban and peri-urban areas were found positive of recent SHS exposure ${ }^{18}$. There is, therefore, an urgent need to reduce exposure to SHS in women and children through implementing effective, affordable, inclusive, feasible and sustainable solutions.

\section{Smoking restrictions at home}

The WHO Framework Convention on Tobacco Control (FCTC) recommends that countries enforce comprehensive smoke-free laws as one of the effective demandreduction tools (Article 8). However, comprehensive smoke-free legislation is only in place in 55 countries, covering just $20 \%$ of the world's population ${ }^{19}$. Among LMICs, only 35 have adopted smoke-free legislation covering all categories of public places such as work sites, bars, restaurants, schools, universities, and healthcare institutions ${ }^{19}$. However, even the most comprehensive legislation would not address SHS exposure in households. Though some evidence suggests
AFFILIATION

1 Department of Economics, University of Dhaka, Dhaka, Bangladesh

2 ARK Foundation, Dhaka,

Bangladesh

3 Department of Health Sciences, University of York, Heslington, United Kingdom

CORRESPONDENCE TO

Rumana Huque. ARK Foundation, 6 Road 109, Gulshan 2, Dhaka,

Bangladesh. E-mail: rumanah14@ yahoo.com ORCID ID: https://orcid.org/00000002-7616-9596

\section{KEYWORDS}

tobacco, secondhand smoke, smoke-free homes, Framework Convention on Tobacco Control

Received: 29 September 2021 Accepted: 1 October 2021 
that smoke-free legislation has a positive effect on promoting smoke-free households ${ }^{20}$. Enforcing smokefree legislation remains weak in LMICs. Low-levels of voluntary restrictions on smoking in households and a high percentage of smokers, predominantly men, smoking in front of women and children are common in LMICs, especially in patriarchal societies. Although comprehensive smoke-free laws can protect non-smokers from SHS in public places and promote adoption of voluntary restrictions in homes, other measures are also required to protect people from SHS exposure at home. For women and children in particular, both smoke-free homes and smoke-free legislation in public places can ensure full protection.

\section{Smoke-free home interventions}

Creating awareness of the adverse consequences of SHS exposure ${ }^{3}$ and encouraging voluntary smokefree rules in homes have been recommended to reduce SHS exposure among women and children and prevent SHS-related diseases and deaths. Clinical interventions delivered in antenatal care settings appear to reduce SHS exposure as pregnancy provides a window of opportunity for the entire family to change harmful behaviors. Schools, primary healthcare facilities and places of worship have been considered as acceptable settings to raise awareness, promote changes in smoking behaviors and reduce SHS exposure at homes ${ }^{4,8}$. The smokefree interventions delivered through school-based and antenatal care settings rely on motivation and ability of children and women, respectively, to persuade smokers to change their behavior. This is particularly challenging in countries where smoking is predominantly a male behavior; for example, in SouthEast Asia the male-female smoking ratio is $16: 1^{21}$. In such places, gender norms favoring male education, health and personal autonomy ${ }^{22}$, with the limited voice of women and children, make confronting smoking at home even more difficult. A number of systematic reviews also concluded that despite several studies on education and counselling programs, their effectiveness in reducing women and children tobacco smoke exposure were not clearly demonstrated ${ }^{17,23}$.

Reducing SHS exposure among women and children would require context-specific interventions that account for the differences in culture, social norms and smoking behaviors across countries $^{4,8,24}$. Rigorous studies, using biochemical validation, are needed to identify the most suitable and relevant strategies for reducing SHS exposure in women and children. Further research is required to test comprehensive community-based interventions through community health workers, religious leaders and schoolteachers to influence smoking behaviors in their communities. A multisectoral approach and further investment are required to enforce smokefree legislation and promote smoke-free homes. This will help achieve the goals set forth in the Sustainable Development Goals (SDGs) of reducing maternal mortality, preventing deaths of newborns and children, and reducing premature mortality from non- communicable diseases.

\section{REFERENCES}

1. GBD 2019 Tobacco Collaborators. Spatial, temporal, and demographic patterns in prevalence of smoking tobacco use and attributable disease burden in 204 countries and territories, 1990-2019: a systematic analysis from the Global Burden of Disease Study 2019. Lancet. 2021;397(10292):2337-2360. doi:10.1016/ S0140-6736(21)01169-7

2. World Health Organization. WHO global report on trends in prevalence of tobacco smoking 2000-2025, 2nd ed. World Health Organization; 2018. Accessed September 21, 2021. https://apps.who.int/iris/handle/10665/272694

3. Wipfil H, Avila-Tang E, Navas-Acien A, et al. Secondhand Smoke Exposure Among Women and Children: Evidence From 31 Countries. Am J Public Health. 2008;98(4):672679. doi:10.2105/AJPH.2007.126631

4. Siddiqi K, Huque R, Kanaan M, et al. Children Learning About Secondhand Smoke (CLASS II): A Pilot Cluster Randomized Controlled Trial. Nicotine Tob Res. 2019;21(5):670-677. doi:10.1093/ntr/nty090

5. World Health Organization. Report of the Global Tobacco Epidemic, 2009: Implementing Smoke-free Environments. World Health Organization; July 9, 2009. Accessed September 21, 2021. https://www.who.int/ publications/i/item/9789241563918

6. World Health Organization. Protection from exposure to second-hand tobacco smoke:policy recommendations. World Health Organization; 2007. Accessed September 21, 2021. https://apps.who.int/iris/handle/10665/43677

7. Reece S, Morgan C, Parascandola M, et al. Secondhand smoke exposure during pregnancy: a cross-sectional analysis of data from Demographic and Health Survey from 30 low-income and middle-income countries. Tob Control. 2019;28(4):420426. doi:10.1136/tobaccocontrol-2018-054288

8. Mdege ND, Fairhurst C, Wang HI, et al. Efficacy and costeffectiveness of a community-based smoke-free-home intervention with or without indoor-air- quality feedback in Bangladesh (MCLASS II): a three-arm, cluster-randomised, 
controlled trial. Lancet Glob Health. 2021;9(5):e639-e650. doi:10.1016/S2214-109X(21)00040-1

9. Leonardi-Bee J, Jere ML, Britton J. Exposure to parental and sibling smoking and the risk of smoking uptake in childhood and adolescence: A systematic review and meta-analysis. Thorax. 2011;66(10):847-855. doi:10.1136/thx.2010.153379

10. Chen R, Clifford A, Lang L, et al. Is exposure to secondhand smoke associated with cognitive parameters of children and adolescents?-A systematic literature review. Ann Epidemiol. 2013;23(10):652-661. doi:10.1016/j.annepidem.2013.07.001

11. Leonardi-Bee J, Britton J, Venn A. Secondhand smoke and adverse fetal outcomes in nonsmoking pregnant women: A meta-analysis. Pediatrics. 2011;127(4):734741. doi:10.1542/peds.2010-3041

12. World Health Organization. Global Adult Tobacco Survey: Fact Sheet Bangladesh 2017. August 7, 2018. Accessed September 21, 2021. https://cdn.who.int/media/docs/ default-source/ncds/ncd-surveillance/data-reporting/ bangladesh/gats/fact-sheet-gats-bangladesh-2017. pdf?sfvrsn=175f043_2\&download=true

13. World Health Organization, Centers for Disease Control and Prevention. Global Adult Tobacco Survey: Fact Sheet China 2018. May 13, 2019. Accessed September 21, 2021. https://www.tobaccofreekids.org/assets/global/pdfs/en/ GATS_China_2018_FactSheet.pdf

14. World Health Organization, Ministry of Health \& Family Welfare. Global Adult Tobacco Survey: GATS-2 India 2016-2017. Accessed September 21, 2021. https://nhm. gov.in/NTCP/Surveys-Reports-Publications/GATS-2Highlights-(National-level).pdf

15. World Health Organization, Centers for Disease Control and Prevention. Global Adult Tobacco Survey: Fact Sheet Indonesia 2011. August 2, 2012. Accessed September 21, 2021. https://cdn.who.int/media/docs/defaultsource/ncds/ncd-surveillance/data-reporting/indonesia/ gats/indonesia-gats-factsheet-8-february-2012. pdf?sfvrsn=d2cd2458_2\&download=true

16. Oberg M, Jaakkola M, Woodward A, et al. Worldwide burden of disease from exposure to second-hand smoke: a retrospective analysis of data from 192 countries. Lancet. 2011;377(9760):139-146. doi:10.1016/S0140-6736(10)61388-8

17. Oberg M, Jaakkola M, Woodward A, et al. Worldwide burden of disease from exposure to second-hand smoke: a retrospective analysis of data from 192 countries. Lancet. 2011;377(9760):139-146. doi:10.1016/S0140-6736(10)61388-8

18. Shah S, Kannan M, Huque R, et al. Secondhand Smoke Exposure in Primary School Children: A Survey in Dhaka, Bangladesh. Nicotine Tob Res. 2019;21(4):416-423. doi:10.1093/ntr/ntx248

19. World Health Organization. WHO Report of the Global Tobacco Epidemic, 2017: Monitoring tobacco use and prevention policies. World Health Organization; 2017. Accessed September 21, 2021. https://apps.who.int/iris/ bitstream/handle/10665/255874/97892415? sequence $=1$

20. Been JV, Nurmatov UB, Cox B, et al. Effect of smokefree legislation on perinatal and child health: a systematic review and meta-analysis. Lancet. 2014;383(9928):15491560. doi:10.1016/S0140-6736(14)60082-9

21. World Health Organization. WHO global report on trends in prevalence of tobacco smoking 2000-2025, third edition. December 18, 2019. Accessed September 21, 2021. https://www.who.int/publications/i/item/whoglobal-report-on-trends-in-prevalence-of-tobacco-use2000-2025-third-edition

22. Jayachandran S. The Roots of Gender Inequality in Developing Countries. Annu Rev Econom. 2015;7:63-88. doi:10.1146/annurev-economics-080614-115404

23. Baxi R, Sharma M, Roseby R, et al. Family and carer smoking control programmes for reducing children's exposure to environmental tobacco smoke. Cochrane Database Syst Rev. 2018;1(1):CD001746. doi:10.1002/14651858.CD001746.pub4

24. Zhou YH, Mak YW, Ho GWK. Effectiveness of Interventions to Reduce Exposure to Parental Secondhand Smoke at Home among Children in China: A Systematic Review. Int J Environ Res Public Health. 2019;16(1):107. doi:10.3390/ijerph16010107

CONFLICTS OF INTEREST

The authors have completed and submitted the ICMJE Form for Disclosure of Potential Conflicts of Interest and none was reported.

FUNDING

There was no source of funding for this research.

ETHICAL APPROVAL AND INFORMED CONSENT

Ethical approval and informed consent were not required for this study.

DATA AVAILABILITY

Data sharing is not applicable to this article as no new data were created.

PROVENANCE AND PEER REVIEW

Commissioned; internally peer reviewed. 